\title{
A review of semi-rigid, stilbene-containing alternating copolymers
}

\author{
Alice M. Savage $\cdot$ Xu Zhou $\cdot$ Jing Huang $\cdot$ \\ S. R. Turner
}

Received: 3 March 2014/Accepted: 17 March 2014/Published online: 16 April 2014

(C) The Author(s) 2014. This article is published with open access at Springerlink.com

\begin{abstract}
The synthesis and properties of sterically congested, stilbene-containing alternating copolymers are reviewed. Persistence lengths $(2-6 \mathrm{~nm})$ determined by size exclusion chromatography and small angle $\mathrm{X}$-ray scattering techniques show that these are semi-rigid copolymers. Fully characterized polyanions and polyampholytes, prepared from organic-soluble precursors were studied, along with their respective salt and $\mathrm{pH}$ response behavior resulting from the semi-rigid polymer backbone. The solidstate characterization from these studies reveals a high degree of hindered rotation along the polymer backbone. The contorted structure and the hindered rotation of the polymer backbone generate inefficient chain packing, which leads to an increase of nanoporosity and higher surface areas. The semi-rigid stilbene-containing copolymers are a new class of copolymers where the increased polymer backbone rigidity leads to a wide range of polymer properties not attained with flexible polymers.
\end{abstract}

Keywords Stilbene - Alternating copolymers · Copolymerization $\cdot$ Maleic anhydride $\cdot$ Maleimides

\section{Introduction}

Substituted stilbenes (1,2-diphenylethylenes) are widely studied and used organic compounds for the optical properties arising from their conjugated ethylene structure, e.g. optical brighteners, dyes, etc. [1, 40]. Many applications of

A. M. Savage $\cdot$ X. Zhou $\cdot$ J. Huang $\cdot$ S. R. Turner $(\square)$ Department of Chemistry MC0212 and Macromolecules and Interfaces Institute MC0344, Virginia Tech, Blacksburg, VA 24061, USA

e-mail: srturner@vt.edu stilbene derivatives have resulted in a large library of substituted stilbene small molecules and facile synthetic techniques to enable synthesis of a variety of derivatives many of which can serve as copolymerizable monomers. However, the addition polymerization and copolymerization of this family of 1,2-disubstituted olefins, like all 1,2substituted ethylene structures, is difficult due to the steric constraints of the 1,2-structure. Homopolymerization of stilbene and substituted stilbenes to the corresponding poly (benzyl) backbone has not been achieved; however, alternating copolymerization of stilbene both anionically [48] and radically [44] is well documented. In alternating copolymerizations, the cross-propagation step is greatly favored since the steric interactions in the cross propagation step are depressed compared to those required for a successful self-propagation of the stilbene monomers. In addition the electronic effects resulting from electron rich and electron poor comonomers cross-propagating with an electron rich or electron poor terminal radical favor fast cross-propagation. Stilbene copolymers have been claimed in the patent literature to be useful in lubricants [37], lubricating oil additives [2, 31], thermal stability additives for photoresists [42], and improved stain resistant polyamide textiles [11], although successful commercialization of these potential applications is not known.

The radical alternating copolymerization of unsubstituted stilbene is the most studied stilbene polymerization $[6,16,35]$. It was found in 1930 that stilbene copolymerized with maleic anhydride [44]. Since neither monomer can undergo radical homopolymerization, these are strictly alternating copolymers with no stilbene-stilbene or maleic anhydride-maleic anhydride dyads present [21]. This study attracted many groups to study the comonomer reactivity ratios [21], monomer sequences [16], thermal stability [32], and copolymerization mechanism [9, 17, 34]. However,

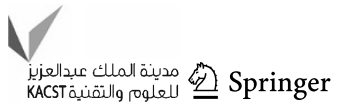


surprisingly limited solubilities and uninteresting brittle materials have slowed detailed investigations of the copolymerizations and the properties of the resulting copolymers [41].

$\mathrm{N}$-substituted maleimides readily radically polymerize with stilbene into predominately alternating copolymer structures-maleimides can radically homopolymerize, so some maleimide-maleimide dyads can be present in these copolymers [19, 35, 46]. Many of these copolymers have limited solubilities in common organic solvents so solution studies are limited.

Our recent work involves the design and synthesis of new stilbene comonomers with specifically chosen functional groups for effecting the copolymerization with maleic anhydride or N-substituted maleimides. Radical polymerization processes are compatible with many functional groups [5] and the alternating nature of the copolymerization enables precise placement of functionality into the copolymer backbones for study of the structure/property relationships of these novel sterically congested backbone polymers in both solution and the solid state.

\section{Monomer substituent effect on copolymerization}

The type and position of substituents on the aromatic groups of stilbene were found to have a significant effect on both the overall copolymerization rates as well as the solubility of the copolymers [24]. Several methyl-substituted stilbene monomers were prepared by using the Wittig-Horner reaction and the resulting monomers were copolymerized with maleic anhydride. Feed ratio/composition studies and ${ }^{13} \mathrm{C}$ NMR confirmed the strictly alternating sequences in the backbone [24]. The methylsubstitution increased the solubility of the copolymers in organic solvents by disrupting copolymer aggregation. This allowed for thorough characterization of these copolymers via SEC, NMR and DLS (dynamic light scattering). We note that with unsubstituted stilbene and maleic anhydride copolymers, strong aggregation in DLS was observed which likely accounts for the "insolubility" of these copolymers as reported in the literature. The location of the methyl groups on the phenyl rings was found to have a strong influence on the overall rate of copolymerization. Methyl groups in the para position led to increase copolymerization rates due to the inductively electron donating characteristics which lead to a more reactive stilbene radical to cross propagate with the electron deficient double bond of maleic anhydride. The ortho-methyl stilbene monomers were found to copolymerize at significantly slower rates due to the loss of conjugation of the aromatic groups with the radical due to steric interactions of the methyl groups forcing the phenyl groups out-of-plane (Fig. 1). DLS measurements showed that the para-substituted stilbene copolymers formed higher molecular weight aggregates in solution, where little aggregation was observed in the ortho substituted samples [24].

Strong electron donating groups, such as dialkyl amino substituents in the para position of stilbene showed extremely high copolymerization rates [29]. Unsymmetrical alkyl substituents on the stilbene comonomers were employed to obtain soluble copolymers. For all of the stilbene copolymers thermal analyses by DSC showed no observable $T_{\mathrm{g}}$ at temperatures $<250{ }^{\circ} \mathrm{C}$ [29].

With the goal of synthesizing a family of precisely functionalized polyanions, both styrene and stilbene (a)<smiles>Cc1ccccc1C(=O)C(c1ccccc1)C1C(=O)OC(=O)C1C(=O)O</smiles>

2MeSti-alt-MAn

Fig. 1 Structures of organic-soluble, main-chain stilbene-containing copolymer precursors. a poly $((E)$-2-methylstilbene-alt-maleic anhydride) (2MeSti-alt-MAn) [24], b poly $\left(N, N, N^{\prime}, N^{\prime}\right.$-tetraalkyl-4,4'-diaminostilbene-alt-maleic anhydride) (TADASti-alt-MAn) [29],<smiles>CC(C)(C)OC(=O)c1ccc(C(c2ccc(C(=O)OC(C)(C)C)cc2)C2C(=O)OC(=O)C2C(F)(F)F)cc1</smiles>

\section{DTBCSti-alt-MAn}

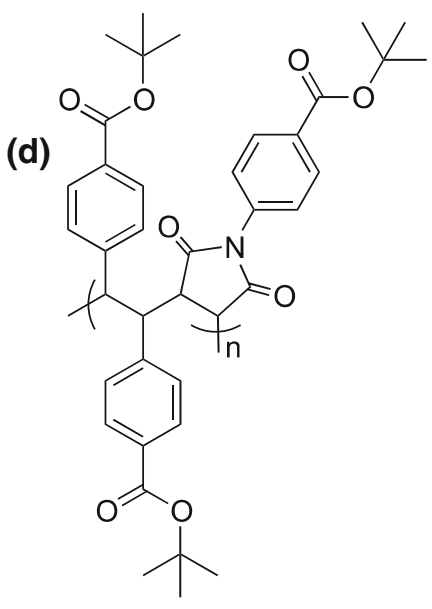

DTBCSti-alt-TBCPMI

c poly((E)-di-tert-butyl 4,4'-stilbenedicarboxylate-alt-maleic anhydride) (DTBCSti-alt-MAn) [22], and d poly((E)-di-tert-butyl 4,4'stilbenedicarboxylate-alt-tert-butyl 4-maleimidobenzoate) (DTBCStialt-TBCPMI) [22] 
monomers were synthesized with tert-butyl ester groups in the para positions [22]. Higher temperatures were required to obtain efficient copolymerizations because of the electron withdrawing nature of the para ester groups. The use of the tert-butyl ester copolymers, as precursors to the polyanions, enabled the accurate determination of the molar mass and molar mass distributions by SEC avoiding the known SEC analysis problems of polyelectrolytes. The tert-butyl ester groups were found to cleanly thermally decompose as determined by the expected weight loss for extrusion of isobutylene in thermal gravimetric analyses [22]. For study of the polyanions, deprotection with trifluoroacetic acid followed by neutralization with base and dialysis yielded the pure, well-characterized polyanions. The solution properties of the precursor tert-butyl ester copolymers and the polyanions were studied in detail [23].

\section{Polymer rigidity}

The early investigation of main-chain stilbene copolymers suggested that they possessed characteristics consistent with rigid rod-like structures. This led to further investigation into the chain stiffness of the copolymer backbone [28-30]. When examining the ${ }^{1} \mathrm{H}$ NMR spectra of any of these copolymers, the backbone and aromatic peaks appeared very broad [24]. When associated with rigid polymers and high molecular weight materials, broad peaks develop due to strong homonuclear dipolar couplings and slow ${ }^{1} \mathrm{H}$ relaxation rates [45]. With no observed $T_{\mathrm{g}}$ below $250{ }^{\circ} \mathrm{C}$, evidence of hindered rotation and limited movement of the polymer backbone pointed to a more rigid polymer backbone with a sterically crowded configuration. In the case of poly $\left(N, N, N^{\prime}, N^{\prime}\right.$-tetraethyl-4, $4^{\prime}$-diaminostilbene-alt-maleic anhydride) (TEDASti-alt-MAn), the copolymer backbone likely conformed into a contorted, sterically crowded conformation with the maleic anhydride units existing predominately in the cis configuration [28] (Fig. 1b).

To confirm the rigidity or chain stiffness of the stilbene alternating copolymers, SEC and SAXS were used to directly measure the chain stiffness (persistence length, $l_{\mathrm{p}}$ ) [25]. Defined as a measure of chain stiffness or rigidity, persistence lengths provide a direct comparison of intrinsic polymer chain stiffness with other flexible and rigid polymers. (E)-di-tert-butyl 4,4'-stilbenedicarboxylate and the styrene analog (tert-butyl 4-vinyl benzoate) were copolymerized with MAn and tert-butyl 4-maleimidobenzoate, respectively. This copolymer series was studied to investigate the effects of the added extra phenyl ring of stilbene monomer and cyclic monomer structure (MAn versus maleimide) on the persistence lengths [22, 25]. Based on

\section{Increasing Persistence Length}

(a)<smiles>CCCC(c1ccc(C(=O)OC(C)(C)C)cc1)C1C(=O)OC(=O)C1C(C)(C)C</smiles>

TBCSty-alt-MAn DTBCSti-alt-MAn

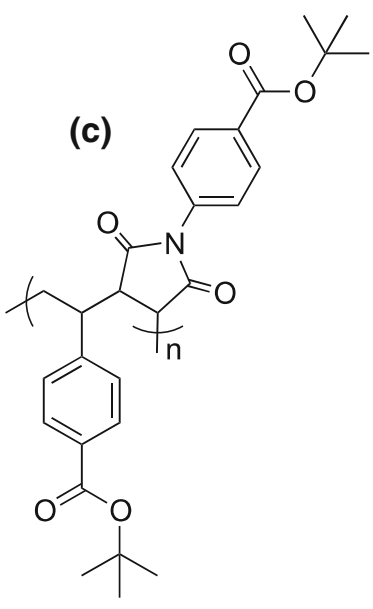

TBCSty-alt-TBCPMI (d)<smiles>CC(C)=C(c1ccc(C(=O)OC(C)(C)C)cc1)C(c1ccc(C(=O)OC(C)(C)C)cc1)C1C(=O)N(c2ccc(C(=O)OC(C)(C)C)cc2)C(=O)C1=C(C)F</smiles>

DTBCSti-alt-TBCPMI
Fig. 2 A series of tert-butyl protected stilbene and styrene containing alternating copolymer precursors in order of increasing rigidity (increases left to right). a poly((tert-butyl 4-vinyl benzoate-alt-maleic anhydride) (CSty-alt-MAn), b poly((E)-di-tert-butyl 4,4'-stilbenedicarboxylate-alt- maleic anhydride) (DTBCSti-alt-MAn), c poly(tert-butyl 4-vinyl benzoate-alt-tert-butyl 4-maleimidobenzoate) (CSty-alt-TBCPMI) and d poly ((E)-di-tert-butyl 4,4'-stilbenedicarboxylate-alt-tert-butyl 4-maleimidobenzoate) (DTBCSti-alt-TBCPMI) [25] 
<smiles>CC(C)(C)C(C(=O)O)C(C(=O)O)C(c1ccccc1)C(C)(C)c1ccccc1</smiles>

Sti-alt-MA

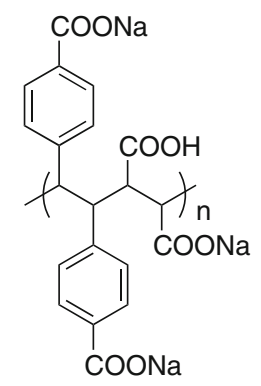

DCSti-alt-MA

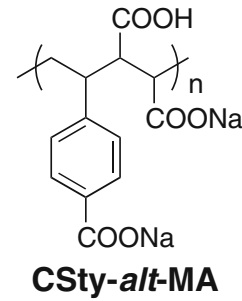

CSty-alt-MA
Fig. 3 Structures of carboxylated stilbene-containing polyanions: poly(stilbene-alt-maleic acid) (Sti-alt-MA), poly $\left(\left(4,4^{\prime}\right.\right.$-stilbenedicarboxylate)-alt-maleic acid) (DCSti-alt-MA), and poly((4-vinyl benzoic acid)-alt-maleic acid) (CSty-alt-MA) [23]

SEC and SAXS methods [3, 4, 38, 39], this copolymers series exhibited the persistence lengths between 2 and $6 \mathrm{~nm}$. From this direct comparison and measurement, stilbene alternating copolymers are classified as semi-rigid polymers (Fig. 2). For example, a typical flexible copolymer, polystyrene, exhibits a persistence length of $0.9 \mathrm{~nm}$ [10] and a rigid copolymer, polyphenylene with sulfonate ester side groups exhibits a persistence length of $13 \mathrm{~nm}$ $[14,43]$. Accordingly, the stilbene-containing copolymers appear $20 \%$ more rigid than the styrene analogs and the maleimide-containing copolymers appear $50 \%$ more rigid than MAn-containing copolymers of the same comonomer. The polymer physical properties that arise from these semirigid and sterically crowded copolymers involve unique solution and solid-state properties.

\section{Solution properties}

Using the same deprotection strategy above, a family of polyanion and polyampholyte copolymers were prepared with stilbene comonomers and the solution properties arising from the semi-rigid copolymer backbone were studied $[22,23,30]$.

\section{Polyanions}

As mentioned above, carboxylated polyanions [22, 25] were synthesized from the deprotection of the precursor copolymers, and fully characterized with respect to molar mass, composition, and intrinsic polymer rigidity. Further physical aqueous solution properties evaluated using steady-state solution shear rheology, dynamic light scattering (DLS), and titration studies proved critical to understanding effects of polymer rigidity and conformation in aqueous solutions [23].

Using steady-state solution shear rheology, reduced viscosity plotted against polymer concentration revealed a

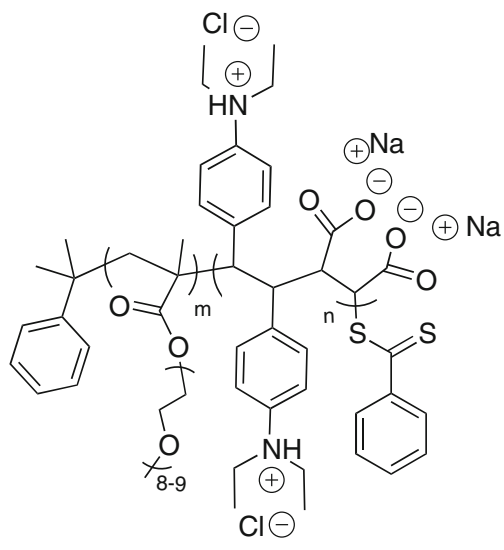

\section{OEGMA-b-(TEDASti-alt-MA)}

Fig. 4 Polyampholyte structure of poly(oligo-(ethylene glycol)methacrylate)- $b$-( ( $N, N, N^{\prime}, N^{\prime}$-tetraethyl-4,4'-diaminostilbene)-alt-maleic acid)) ((OEGMA- $b$-(TADASti-alt-MA))) [30]

prominent polyelectrolyte effect in deionized water for DCSti-alt-MA, CSty-alt-MA, and Sti-alt-MA shown in Fig. 3 [23]. Increasing the sodium chloride $(\mathrm{NaCl})$ concentration suppressed the polyelectrolyte effect by decreasing the Debye Length and electrostatic repulsions as the polymer concentration decreased. These results were consistent with semi-rigid polymers.

The statistical segment length $\left(L_{\mathrm{k}}\right)$ for each copolymer with or without $\mathrm{NaCl}$ was measured by adding the intrinsic statistical segment length $\left(L_{0}\right)$ to the electrostatic statistical segment length $\left(L_{\mathrm{e}}\right)$ [7, 8, 47]. In deionized water, the carboxylated copolymers behaved like rigid-rods due to strong electrostatic repulsions and the statistical segment lengths decreased as $\mathrm{NaCl}$ concentration increased. Thus, the polyanions behaved like semi-rigid copolymers in $\mathrm{NaCl}$ solutions and followed the same rigidity trends established for the intrinsic statistical segment lengths above [25].

To further characterize the polymer properties in aqueous solutions, $\mathrm{pH}$ titration was used to evaluate the dissociation behavior of the polyanions. Titration results revealed multiple inflection points arising from the two vicinal carboxylic acid groups. Due to the close proximity of the diacids, each carboxylic acid has a distinct pKa and dissociates at different $\mathrm{pH}$. This is consistent with poly(styrene-alt-maleic acid) (Sty-alt-MA) titration results [12].

\section{Polyampholytes}

The first stilbene-containing polyampholyte diblock copolymers were prepared using RAFT (reversible addition fragmentation chain transfer) polymerization techniques [30]. The diblock copolymer, poly(OEGMA- $b$-(TADAStialt-MAn)), consisted of a polymerized methoxy-capped 
Fig. 5 Structures of maleimide copolymers with stilbene and styrene analogs. a poly(styrenealt- $N$-(2-methylphenyl) maleimide) (Sty-alt-2MePMI); b poly(stilbene-alt- $N$-phenyl maleimide) (Sti-alt-NPMI); c poly(stilbene-alt- $N$-(2methylphenyl) maleimide) (Sti-alt-2MePMI) [27] (a)

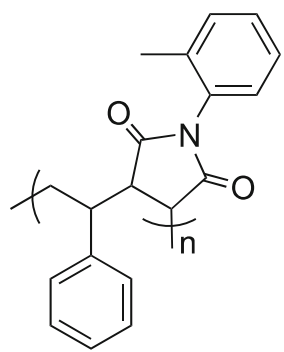

Sty-alt-2MePMI oligo-(ethylene glycol)methacrylate) (OEGMA) block chain extended with $N, N, N^{\prime}, N^{\prime}$-tetraethyl-4,4'-diaminostilbene and MAn [30]. After molar mass determination in organic solvent, the block copolymer converted to its subsequent polyampholyte (Fig. 4) via simple acid hydrolysis. The resulting water-soluble polyampholyte ((OEGMA- $b$-(TADASti-alt-MA))) formed polyion complexes (PICs) and exhibited a $\mathrm{pH}$ and salt responsiveness atypical of polyampholytes.

To evaluate the PIC aggregate response to $\mathrm{pH}$ and salt concentration, DLS was used to monitor the aggregate size. The aggregate size increased as the $\mathrm{pH}$ approached the isoelectric point (IEP) of the polyampholyte. For more flexible and non-flexible polyampholytes, as the $\mathrm{pH}$ neared the IEP, the copolymer chains expand as the electrostatic attractive forces decrease $[13,26]$. Atypical for polyampholytes, adding $\mathrm{NaCl}$ to the [(OEGMA- $b$-(TADASti-alt-MA))] copolymer solution increased the PIC size even as the electrostatic repulsions decrease. The "like-charge" attraction of the polymer chains causes polymer chains to aggregate and increase PIC size $[15,18,20]$. The semi-rigid polymer backbone of the TADASti-alt-MA block facilitated dipoledipole interactions of condensed counter-ions and induced the "like-charge" attraction $[18,20]$. Ongoing work involves investigating the effects of charge density, molar mass, and linear, water-soluble homopolymer blocks [36].

\section{Solid-state properties}

Forming brittle films when cast from solution, the semirigid copolymers offer unique solid-state properties like birefringence and nanoporosity as a result of the sterically crowded copolymer backbones. Hindered rotations and inefficient chain packing of the copolymer backbone significantly affects and enhances the solid-state properties.

A series of methyl-substituted maleimide copolymers with stilbene and styrene analog films exhibited large negative birefringence up to 0.02 for Sti-alt-2MePMI (Fig. 5) [27]. During casting of the film, the ortho-methyl forced the phenyl groups to align normal to the imide (b)

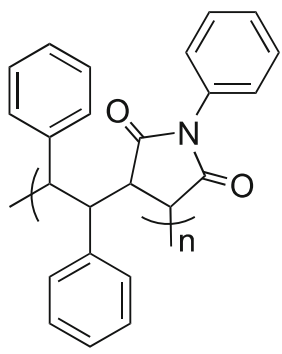

Sti-alt-NPMI (c)<smiles>Cc1ccccc1N1C(=O)C(C(c2ccccc2)C(C)(C)c2ccccc2)C(C(F)(F)F)C1=O</smiles>

Sti-alt-2MePMI plane. Due to the anisotropy of the benzene ring, the alignment of the phenyl rings, and the restricted rotation induced a negative birefringence [33]. The same effect did not appear in Sti-alt-NPMI (Fig. 5b) without the orthomethyl substituent; thus, the phenyl rings freely rotated. The less sterically crowded Sty-alt-2MePMI (Fig. 5a) showed a low negative birefringence of 0.002 which indicated that the sterically crowded polymer backbone influences the free rotation of the phenyl rings.

The nanoporous characteristics of the same series of tert-butyl carboxylate functionalized alternating copolymers using nitrogen adsorption/desorption isotherms and atomistic molecular simulations were studied (Fig. 2) [49]. These alternating copolymers showed a nanoporosity with Brunauer-Emmett-Teller (BET) surface area of $20-40 \mathrm{~m}^{2} /$ g. This is likely due to the insufficient chain packing of these semi-rigid polymer chains and the increase in the internal free volume leads to an increased surface area. Also, as the chain rigidity increased, then the BET surface areas increased for this copolymer series [49].

\section{Conclusions}

This review highlights the synthesis and properties of sterically crowded stilbene-containing copolymers. The alternating copolymerization gives precise control over monomer sequence, which affords precise placement of functional groups along the polymer backbone. With precise control over monomer sequence, stilbene-containing alternating copolymers afford semi-rigid copolymers. Both the solution and solid-state properties confirm the semirigid nature of the backbone. Continued research on stilbene-containing copolymers and block copolymers is focused on new polymeric derivatives to explore the wide range of solid state and solution properties that result from the semi-rigid backbone characteristics.

Acknowledgments National Science Foundation Grant Numbers DMR 9905231 and 1206409 supported fundamental studies on the synthesis, characterization, solution and solid properties of the alternating copolymers in this manuscript. 
Open Access This article is distributed under the terms of the Creative Commons Attribution License which permits any use, distribution, and reproduction in any medium, provided the original author(s) and the source are credited.

\section{References}

1. Henkel-Helios A (1959) Detergent compositions. United Kingdom Patent 810,151

2. Anderson WS (1967) Copolymers of ethylene and stilbene for use as lubricant additives. U.S. Patent 3,338,877

3. Beaucage G, Rane S, Sukumaran S, Satkowski MM, Schechtman LA, Doi Y (1997) Persistence length of isotactic poly(hydroxy butyrate). Macromolecules 30(14):4158-4162. doi:10.1021/ ma970373t

4. Bohdanecky M (1983) New method for estimating the parameters of the wormlike chain model from the intrinsic viscosity of stiffchain polymers. Macromolecules 16(9):1483-1492. doi:10.1021/ ma00243a014

5. Braunecker WA, Matyjaszewski K (2007) Controlled/living radical polymerization: features, developments, and perspectives. Prog Polym Sci 32(1):93-146. doi:10.1016/j.progpolymsci.2006. 11.002

6. Chu Q, Lu H, He T, Ding M (2000) Synthesis and thermal polymerization of a novel stilbene-maleimide $\mathrm{AB}$-monomer. Polym Bull 43(6):471-475. doi:10.1007/s002890050003

7. Davis RM, Russel WB (1986) On the theory of dilute polyelectrolyte solutions: extensions, refinements, and experimental tests. J Polym Sci B Polym Phys 24(3):511-533. doi:10.1002/polb. 1986.090240304

8. Davis RM, Russel WB (1987) Intrinsic viscosity and Huggins coefficients for potassium poly(styrenesulfonate) solutions. Macromolecules 20(3):518-525. doi:10.1021/ma00169a009

9. Ebdon JR, Hunt BJ, Hussein S (1987) Radical copolymerization of maleic-anhydride with trans-stilbene. Brit Polym J 19(3-4):333-337

10. Fetters L, Lohse D, Colby R (2007) Physical Properties of Polymers Handbook. In: Mark JE (ed). Springer, New York, p 447

11. Fitzgerald PH, Rao NS, Vinod YV, Henry GK, Prowse KS (1989) Stain-resistant aromatic/maleic anhydride polymers. EP Patent $0,329,899$

12. Garrett ER, Guile RL (1951) Potentiometric titrations of a polydicarboxylic acid: maleic acid-styrene copolymer. J Am Chem Soc 73:4533-4535

13. Gotzamanis G, Tsitsilianis C (2006) Stimuli-responsive A-b-(Bco-C) diblock terpolymers bearing polyampholyte sequences. Macromol Rapid Commun 27(20):1757-1763. doi:10.1002/marc. 200600469

14. Guilleaume B, Blaul J, Ballauff M, Wittemann M, Rehahn M, Goerigk G (2002) The distribution of counterions around synthetic rod-like polyelectrolytes in solution, a study by small-angle $\mathrm{X}$-ray scattering and by anomalous small-angle X-ray scattering. Eur Phys J E 8(3):299-309. doi:10.1140/epje/i2001-10105-8

15. Ha BY, Liu AJ (1997) Counterion-mediated attraction between two like-charged rods. Phys Rev Lett 79(7):1289-1292. doi:10. 1103/PhysRevLett.79.1289

16. Ha NTH (1998) Determination of triad sequence distribution of copolymers of maleic anhydride and its derivatives with donor monomers by $13 \mathrm{C}$ NMR spectroscopy. Polymer 40(4):1081-1086. doi:10.1016/s0032-3861(98)00313-9

17. Hallensleben ML (1973) Electron donor-acceptor complexes and polymerization. V. Copolymerization of maleicanhydride and trans-stilbene under ultraviolet irradiation. Eur Polymer $\mathrm{J}$ 9(3):227-231. doi:10.1016/0014-3057(73)90130-4

18. Hampton KW Jr, Ford WT (2000) Styrylmethyl(trimethyl)ammonium methacrylate polyampholyte latexes. Macromolecules 33(20):7292-7299. doi:10.1021/ma000447s

19. Hayakawa K, Kawase K, Yamakita H (1985) On the reaction mechanism of gamma-ray solid-state copolymerization. J Polym Sci Polym Chem Ed 23(11):2739-2746. doi:10.1002/pol.1985. 170231102

20. Lee K-C, Borukhov I, Gelbart William M, Liu Andrea J, Stevens Mark J (2004) Effect of mono- and multivalent salts on angledependent attractions between charged rods. Phys Rev Lett 93(12): 128101

21. Lewis FM, Mayo FR (1948) Copolymerization. IX. Comparison of some cis and trans isomers. J Am Chem Soc 70:1533-1536

22. Li Y, Mao M, Matolyak LE, Turner SR (2012) Sterically crowded anionic polyelectrolytes with tunable charge densities based on stilbene-containing copolymers. ACS Macro Lett 1(2):257-260. doi:10.1021/mz200061w

23. Li Y, Savage AM, Zhou X, Richard Turner S, Davis RM (2013) Solution properties of stilbene-containing sterically crowded alternating polyanions. J Polym Sci B Polym Phys 51(21):1565-1570. doi:10.1002/polb.23370

24. Li Y, Turner SR (2010) Free radical copolymerization of methyl substituted stilbenes with maleic anhydride. Eur Polym J 46(4):821-828. doi:10.1016/j.eurpolymj.2009.12.013

25. Li Y, Zhang M, Mao M, Turner SR, Moore RB, Mourey TH, Slater LA, Hauenstein JR (2012) Chain stiffness of stilbene containing alternating copolymers by SAXS and SEC. Macromolecules 45(3):1595-1601. doi:10.1021/ma202406a

26. Lowe AB, McCormick CL (2002) Synthesis and solution properties of zwitterionic polymers. Chem Rev 102:4177-4189

27. Mao M, England J, Turner SR (2011) Alternating stilbene copolymers with negative birefringence. Polymer 52(20):4498-4502. doi:10.1016/j.polymer.2011.08.009

28. Mao M, Kim C, Wi S, Turner SR (2008) Chain structure of substituted stilbene-maleic anhydride alternating copolymer probed by solid-state NMR. Macromolecules 41(2):387-389. doi:10.1021/ma702089e

29. Mao M, Turner SR (2006) Synthesis and characterization of highly functionalized polymers based on $\mathrm{N}, N, N^{\prime}, N^{\prime}$-tetraalkyl4, $4^{\prime}$-diaminostilbene and maleic anhydride. Polymer 47(24):8101-8105. doi:10.1016/j.polymer.2006.09.031

30. Mao M, Turner SR (2007) Aggregation of rod-coil block copolymers containing rigid polyampholyte blocks in aqueous solution. J Am Chem Soc 129(13):3832-3833. doi:10.1021/ja070422+

31. Marvel CS, Anderson WS (1954) Copolymerization of 1,3butadiene with some polynuclear aromatic hydrocarbons. J Am Chem Soc 76:5434-5435. doi:10.1021/ja01650a051

32. McNeill IC, Polishchuk AY, Zaikov GE (1995) Thermal degradation studies of alternating copolymers. III. The copolymer of maleic anhydride with trans-stilbene. Polym Degrad Stab 47(2):319-329. doi:10.1016/0141-3910(94)00136-v

33. Riande E, Sáiz E (1992) Dipole moments and birefringence of polymers. Prentice Hall, Michigan

34. Rzaev ZM, Zeinalov IP, Medyakova LV, Babaev AI, Agaev MM (1981) Mechanism of radical copolymerization of maleic anhydride with trans-stilbene. Vysokomol Soedin Ser A 23(3):614-618

35. Rzaev ZMO, Milli H, Akovali G (1996) Complex-radical alternating copolymerization of trans-stilbene with $\mathrm{N}$-substituted maleimides. Polym Int 41(3):259-265. doi:10.1002/(sici)10970126(199611)41:3<259:aid-pi591>3.0.co;2-9

36. Savage AM, Turner SR (2014). Unpublished work

37. Schaschel ET (1975) Reaction products of silicon monoxide and olefins. U.S. Patent 3,907,750 
38. Schmid CW, Rinehart FP, Hearst JE (1971) Statistical length of DNA from light scattering. Biopolymers 10(5):883-893. doi:10. 1002/bip.360100511

39. Sharp P, Bloomfield VA (1968) Light scattering from wormlike chains with excluded volume effects. Biopolymers 6(8):1201-1211. doi:10.1002/bip.1968.360060814

40. Smtih RE (2000) Stilbene dyes. Kirk-Othmer encyclopedia of chemical technology, vol 27, 4th edn. John Wiley \& Sons, Inc, New Jersey

41. Tanaka T, Vogl O (1982) Head-to-head poly(methyl cinnamate) from alternating stilbene-maleic anhydride copolymer, \{poly[1,2bis(methoxycarbonyl)-3,4-diphenyltetramethylene]\}. Macromol Synth 8:21-24

42. Turner SR, Arcus R, Houle C, Schleigh W (1986) High-Tg basesoluble copolymers as novolac replacements for positive photoresists. Polym Sci Eng 26(16):1096-1100

43. Vanhee S, Rulkens R, Lehmann U, Rosenauer C, Schulze M, Koehler W, Wegner G (1996) Synthesis and characterization of rigid rod poly(p-phenylenes). Macromolecules 29(15):5136-5142. doi: $10.1021 / \mathrm{ma} 960124 \mathrm{p}$
44. Wagner-Jauregg T (1930) Additive heteropolymerization. Berichte der Deutschen Chemischen Gesellschaft [Abteilung] B: Abhandlungen 63B:3213-3224

45. Weigand F, Fulber C, Blumich B, Spiess HW (1994) Spatially resolved NMR of rigid polymers and elastomers. Magn Reson Imaging 12(2):301-304. doi:10.1016/0730-725x(94)91541-5

46. Yamakita H, Hayakawa K (1972) Copolymerization of $N$-ethylmaleimide with stilbenes. J Polym Sci A-1 Polym Chem 10(8):2223-2235. doi:10.1002/pol.1972.150100803

47. Yamazaki S, Muroga Y, Noda I (1999) Persistence lengths of ionenes in methanol. Langmuir 15(12):4147-4149. doi:10.1021/ la981120b

48. Yuki H, Okamoto Y, Tsubota K, Kosai K (1970) Anionic copolymerizations of trans-stilbene with butadiene, isoprene, and 2,3-dimethylbutadiene. Polym J 1(2):147-154. doi:10.1295/ polymj.1.147

49. Zhou X, Li Y, Hart KE, Abbott LJ, Lin ZX, Svec F, Colina CM, Turner SR (2013) Nanoporous structure of semirigid alternating copolymers via nitrogen sorption and molecular simulation. Macromolecules 46(15):5968-5973. doi:10.1021/Ma4006582 